\title{
NON-DESTRUCTIVE TECHNIQUES IN THE CONSOLIDATION WORKS OF THE CHURCH OF S.M. OF ITRIA IN PIAZZA ARMERINA (ITALY)
}

\author{
TIZIANA BASIRICO ${ }^{1 *}$, SAMANTHA CAMPIONE ${ }^{1}$ AND ANTONIO COTTONE ${ }^{2}$ \\ ${ }^{1}$ Faculty of Engineering and Architecture \\ University of Enna Kore (UKE) \\ Via delle Olimpiadi, 94100 Enna, Italy \\ e-mail: tiziana.basirico@unikore.it,www.unikore.it (*corresponding author) \\ ${ }^{2}$ Department of Architecture (DARC) \\ University of Palermo (UNIPA) \\ Viale delle Scienze, 90128 Palermo, Italy \\ e-mail: antonio.cottone@unipa.it, www.unipa.it
}

Keywords: Historical structure, masonry, foundation, non-destructive inspection

\begin{abstract}
A real case of consolidation works is presented in which only field testing methods can reveal the causes of instability. This paper is an update of the one presented at the SAHC 2018 conference, concerning the study of the partial collapse of the Church of Itria in Piazza Armerina (Sicily, Italy). The previous paper beared hypotheses and design solutions based only on indirect investigations, theoretical formulations and checks with software. The consolidation works, started in November 2018 and still in progress, have made it possible to formulate new and documented hypotheses on the collapse and to integrate and partly modify the solutions hypothesized previously. In particular, the reconstruction techniques of the wall and chains have been confirmed. The new interventions have, instead, concerned the consolidation of the foundation soil which was found to be insubstantial, following electrical tomographic investigations, due to the presence of voids. At the same time, inspections were carried out on an old masonry sewage pipe which revealed several points of discontinuity through which large quantities of water entered under the walls of the church causing the removal of inconsistent elements from the ground. At first, the reconstruction of the collapsed wall was done and the restoration of the existing wall structures, to eliminate the causes of the collapse through the intervention on the sewage pipe and filling the voids under the foundations. The most important intervention, which required the use of innovative materials, forefront equipment and skilled labor, involved the filling the voids under the foundations through perforations every $50 \mathrm{~cm}$, both on the inner and outer wire of the collapsed wall. Clamped canes were set in order to intercept the voids highlighted by the tomography. A 100\% expansive mortar was injected at low pressure through the canes, filling one cane at a time and progressively raising the point of exit of the mortar until the higher far end. After this consolidation, the foundation and the wall were rebuilt with local limestone ashlars to have fair faced aspect as the original masonry. At the end of the work, further tomographic tests are planned to verify the validity of the interventions carried out.
\end{abstract}




\section{INTRODUCTION}

Preliminary investigations for the knowledge of the building and its site play a fundamental role in restoration and recovery.

The definition of an investigation program often requires an interdisciplinary approach, which goes far beyond simple technical aspects; historical research can be directed to discover phenomena that have involved structural behaviour and, conversely, the analysis of structural behaviour can provide elements that help the recovery designer to find answers to his hypotheses.

A preliminary inspection of site and construction must guide the definition of the investigation plan as these can be carried out at different levels of extension and depth, with consequent different economic and time commitments. The investigation plan must, therefore, be adequate to the complexity, the architectural value of the building, the structural problems to be solved and the possibility to have real benefits from the relative deepening of knowledge.

It is sometimes convenient to start with a minimum investigation plan and then, when and where necessary, to deepen it in later stages.

It is important and this case proves it, not to limit to the analyses necessary to draw up a correct executive project, but to foresee an integration of the investigations during the construction site and continuous monitoring [1].

This methodological approach is simple to apply when it is used in the recovery of a single monument and the restoration operation is, therefore, facilitated as it is limited to a specific

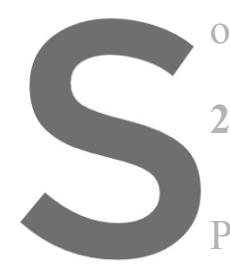

object, whose use is known.

2 THE CASE STUDY

In the previous SAHC

Piazza Armerina (EN) a fro
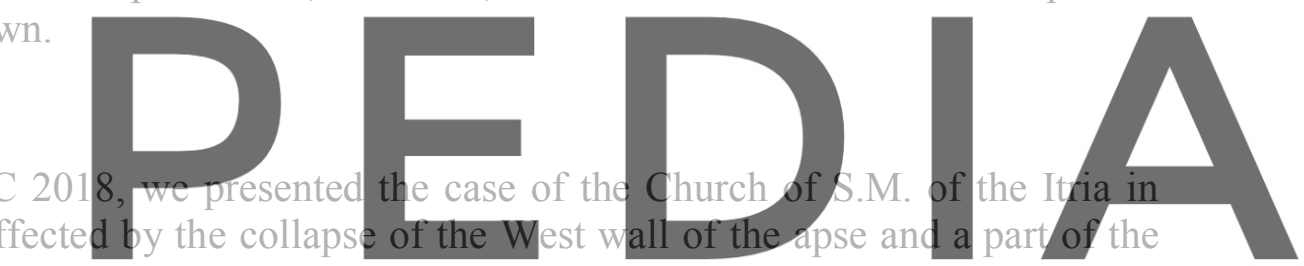

adjacent wall of the lateral nave, which happened during the 29 December 2007 night [2]. In

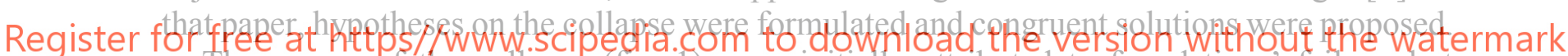
The causes of the collapse (fig. 1) were initially attributed to foundations failure, but geological and geotechnical tests, carried out by the municipality and the Curia of Piazza Armerina, stated the substantial geological stability of the site and the absence of slipping surfaces along which a landslide could occur. It was, therefore, excluded that it was foundations' failure of the wall which did not show, in the visible part, lowering.

From the historical investigation [3], by means of documents, drawings and photographs, important information was obtained on the state of the church, before the collapse, and on previous maintenance and restoration interventions, thus being able to define the historical evolution, including any transformations of the monument.

Analysing the drawings of the previous projects, it was evident the collapse occurred in correspondence to a discontinuity of the wall, due to the construction of a niche; the photographs highlighted the masonry, consisting of irregular stone, had a reduced interlocking between the orthogonal walls. Furthermore two vertical cracks were detected. This led to the hypothesis that the most probable cause of the collapse could be attributed to the higher load on the wall, due to the replacement, occurred in the 1980s, of the existing wooden roof with an iron and brick floor. The new roof was connected to reinforced concrete curbs, placed over the longitudinal load-bearing walls and on the walls above the transverse arches. 



Figure 1: Pictures of the collapse from the outside and inside the church

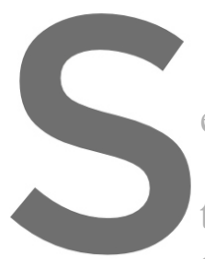
This new static scheme changed the load
eccentric due to the reduced thickness of the cur
With the knowledge hitherto acquired, a kine
that had produced a deformation of the wall, wit
section and breaking due to peak load. By compar

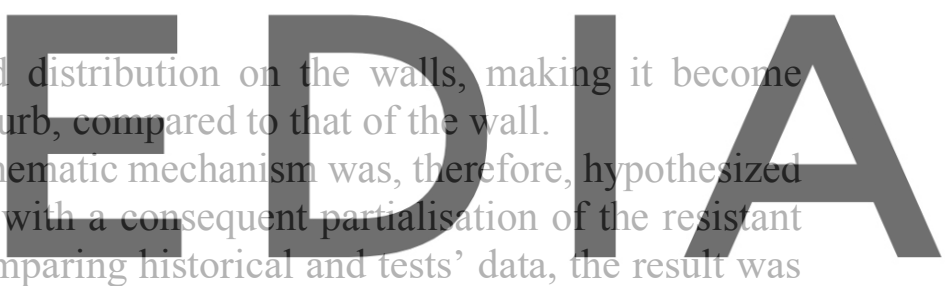
the intervention carried out in the 1980s had accelerated the degradation process and had been



Aware that the removal of the current roof structures would have caused incalculable damages to the monument, it was decided not to intervene on them and rebuild the wall by eliminating the previous discontinuities and consolidating the existing walls.

\section{THE CONSTRUCTION SITE AND THE NEW INVESTIGATIONS}

Once the construction site was set up, on 8 November 2018, the cracking situation was significantly worsened compared to the survey carried out in the design phase, mainly concerning cracks on the floor with relative failure of the pillar, near the apse, due to heavy rains that occurred at the end of October.

This situation led to investigate, through punctual excavations, the conditions of the foundations of the collapsed wall to identify the plan from which to begin the reconstruction.

The excavation work, begun under the collapsed wall at the apse, showed an evident rotation of the lower part of the wall collapsed (fig. 2) and traces of an underground compartment, which led to the need to integrate previous punctual investigations with tests on the entire subsoil of the church. This was necessary in order to have an updated situation after 12 years from the collapse and check the presence of potential underground masonry structures and cavities. 
A geophysical investigation was, therefore, commissioned highlighting a completely different picture of the causes of the collapse and led to the drafting of a variation report.

Following the results of the new investigations, it was decided to carry out inspections inside the underground masonry conduct, in parallel to the wall of the church on Itria St., which conveys the white-water from the mountain and collects dispersed water.
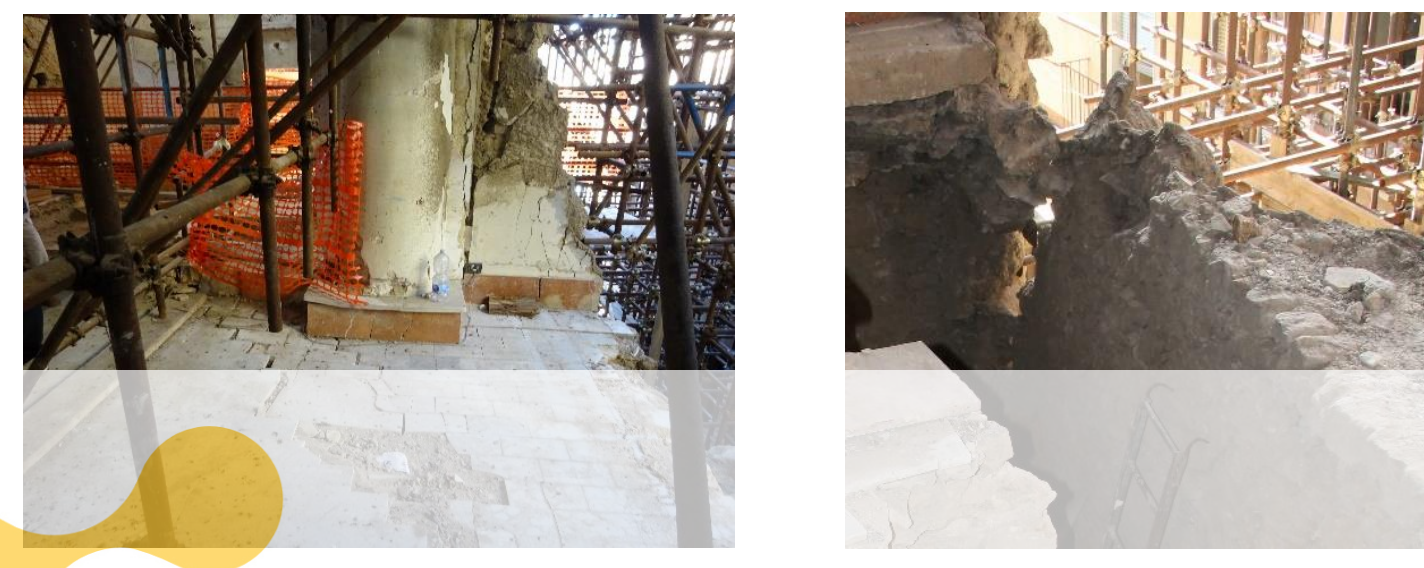

Figure 2: Crack on the floor in proximity of the pillar and the rotation of the wall under the collapsed one

3.1 Application of electric tomography to the case study



3D electrical tomography allowing to assess the resi (1,2 and 3$)$ to define the resolution all the elem anomalies of the stratigr


In particular, the electrodes were positioned externally, along via Itria, the area affected by

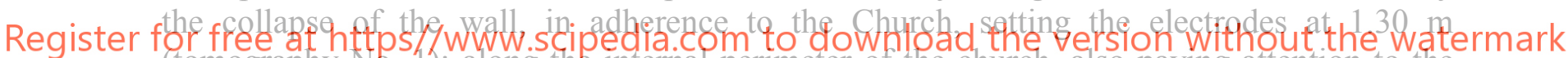
(tomography No. 1); along the internal perimeter of the church, also paying attention to the colonnade foundations of the right nave of the church, due to the lowering of the column near the apse, setting the electrodes at $1 \mathrm{~m}$ (tomography No. 2); inside and outside the wall of the church adjacent to the sacristy, setting the electrodes at $1.30 \mathrm{~m}$ (tomography No. 3) (fig. 3).

The electrodes, consisting of metal pegs, and the energizer producing electricity to be set into the ground, were connected to a data acquisition center. The investigated area was thus ideally divided into a finite number of meshes and cells (the so-called "finite elements"), each of homogeneous and unknown resistivity. In tomographic reconstruction, the unknown is the distribution of the resistivity in the ground, while the electrical measurements carried out on the ground represent the known terms. From an operational point of view, the method consists of transmitting electricity into the ground through an energizing dipole, and measuring the potential difference induced by the electric field created in the ground, by means of a reading dipole. The measurements were recorded by alternately moving (with automatic method) the electricity dipole and the voltage dipole, in order to obtain a mesh of reading points arranged along the three cross-sections. Knowing the potential difference and the electricity intensity in the various points, the apparent resistivity was obtained at each point by applying, by means of special software, the theory of infinitesimal dipoles [6]. 

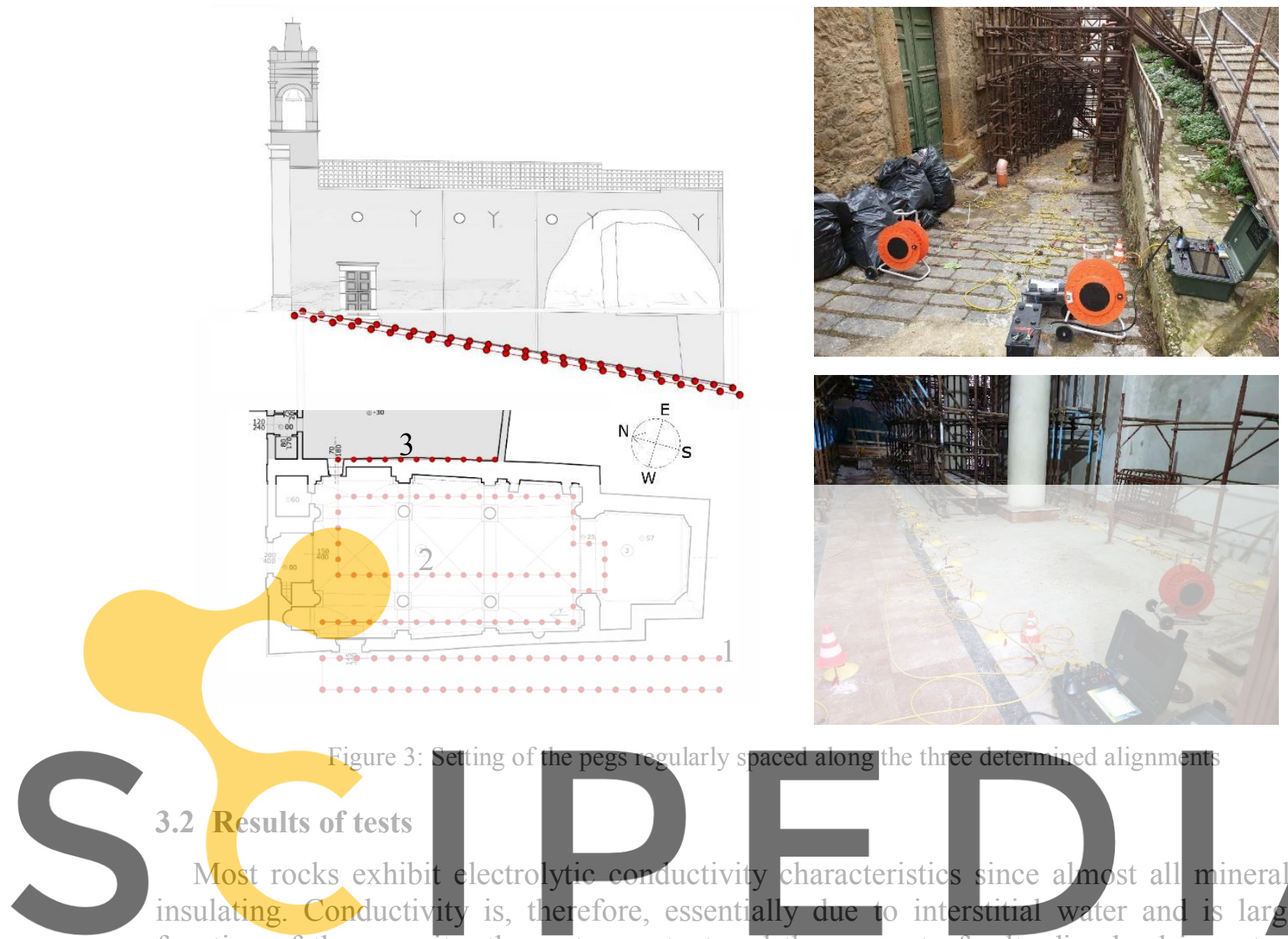

Figure 3 : Setting of the pegs regularly spac
3.2 Results of tests
Most rocks exhibit electrolytic conductivity
insulating. Conductivity is, therefore, essential
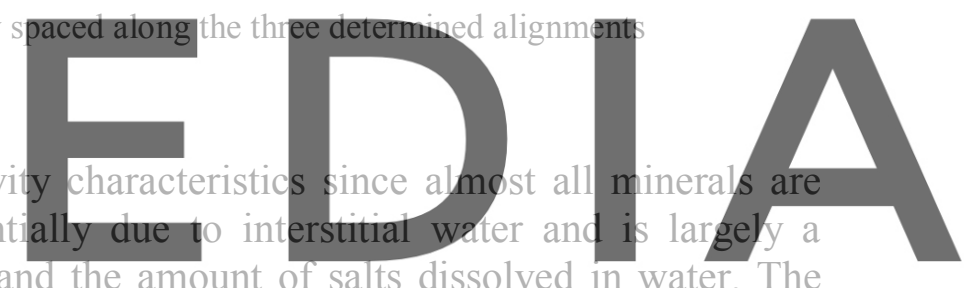

function of the porosity, the water content and the amount of salts dissolved in water. The

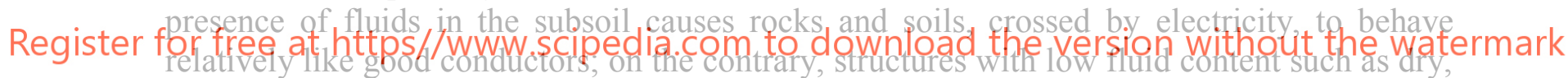
unfracted rocks and natural or man-made cavities behave like bad conductors, if not actually insulators. Therefore, the underground structures respond to the electricity flow, introduced in different ways, according to the physical parameter that regulates this behaviour: the electrical resistivity $\rho$.

Once the apparent resistivity values for the points of the mesh in the established cross-section were obtained, by means of the ERT LAB software, a 3D model of resistivity was obtained allowing giving a qualitative interpretation about the presence of anomalies in the ground thickness divided, as previously exposed, into three-dimensional elements [7].

The elaboration of the electrical tomographies performed allowed acquiring information on the ground the Church of Itria rests on, about the potential presence of voids and/or decompressed material, as well as information on the consistency of ground materials.

In particular, the results show that:

Tomography No. 1: the portion of ground investigated consists almost entirely of medium saturated sands, with resistivity values between $10 \Omega \cdot \mathrm{m}$ and $100 \Omega \cdot \mathrm{m}$. Some areas have been identified along the electrical spreading line with significant deformations of the induced electric field, such as to define areas corresponding to decompressed material and/or the 
presence of potential voids, with resistivity between $160 \Omega \cdot \mathrm{m}$ and $300 \Omega \cdot \mathrm{m}$, affecting thicknesses up to $2 \mathrm{~m}$ deep from the road surface. The volume of these degraded thicknesses was defined by the evaluation of the ZY cross-section. In particular, from the documents referring to tomographic cross-section 1, we highlighted the critical points of the areas presenting significant deformation of the electric field and having probably triggered the failure at the base of the building, due to potential reflux phenomena at the base, with the consequent collapse of the wall along Itria Street

Tomography No. 2: the ground inside the church consists almost entirely of dry filling material, with resistivity between 10 and $100 \Omega \cdot \mathrm{m}$. In particular, it is clear that this filling material is located in the central nave of the church up to $3 \mathrm{~m}$ deep (fig. 4). This result led to the hypothesis of the presence of a pre-existing structure subsequently filled, a crypt or a passage, part of the XIVth century church, some news had been found by means of preliminary historical research. This hypothesis was subsequently confirmed by the discovery, following the excavations, of an underground room below the apse (an area not affected by the tomographic survey) connected through a door to the part below the central nave.

The analysis of the XY sections (fig. 5), at depths varying from $2 \mathrm{~m}$ to $6 \mathrm{~m}$, shows areas of the ground with significant deformations of the induced electric field. Such areas correspond to decompressed material and/or partial presence of voids, already starting from the depth of about $1 \mathrm{~m}$ of the portion of the southeast corner building. These areas are increasing in depth and breadth at the collapsed wall between $150 \Omega \cdot m$ and $200 \Omega \cdot m$, with deformations superimposable with those already detected in tomography No. 1. With the investigation carried $300 \Omega \cdot \mathrm{m}$, at the pillar near the apse affected by the collapse.
Tomography No. 3: the arca investigated with this tomography consists almost entireky of
filling material, except for some areas of the ground with significant efeformations of the
induced electric field. Such areas correspond to buried wall stiuctures with resistivity betw een $160 \Omega \cdot m$ and $300 \Omega \cdot m$, present up to a depth of approximately $1.6 \mathrm{~m}$ from the floor. Register for free at https//www.scipedia.com to download the version without the watermark

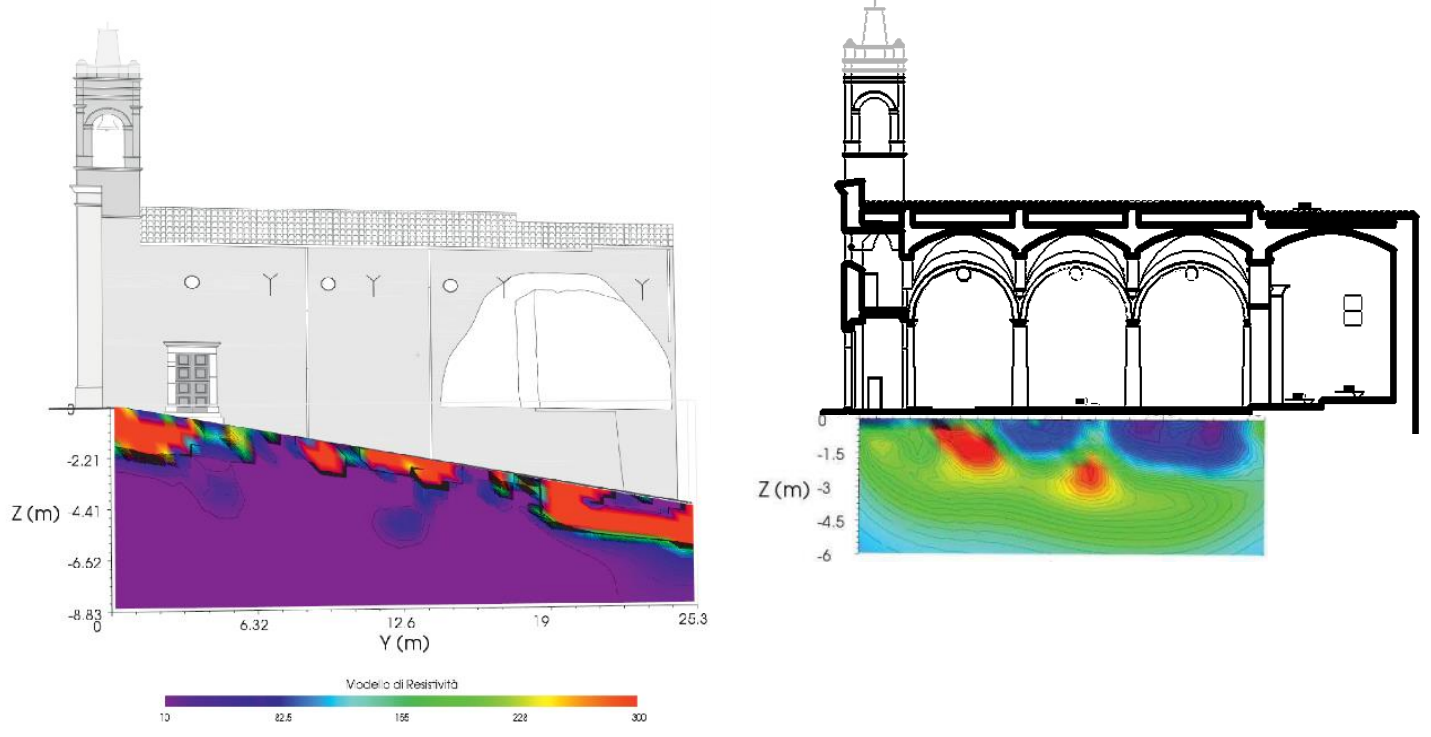

Figure 4: Results of tomography No. 1 and No. 2 

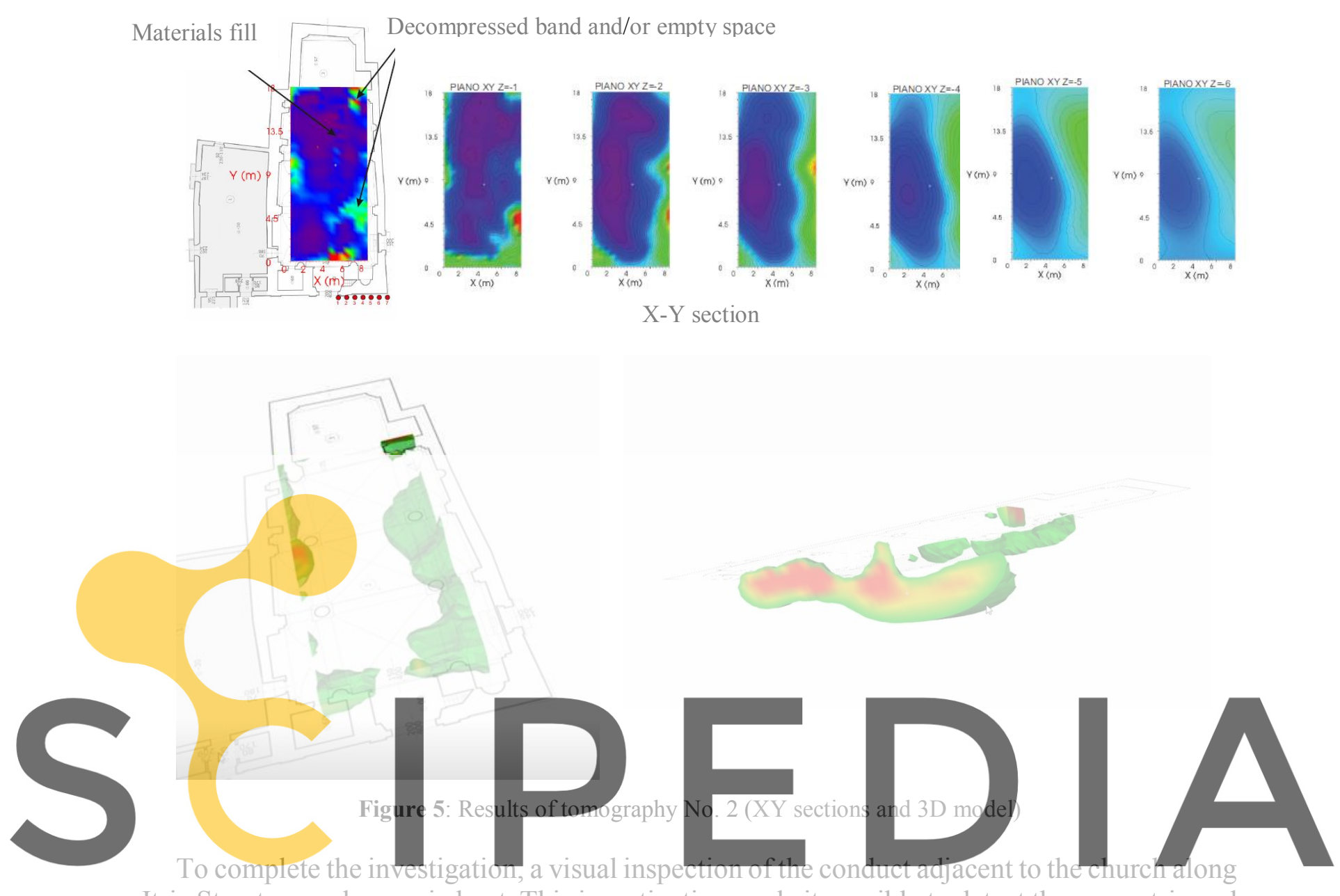

Itria Street, was also carried out. This investigation made it possible to detect the geometric and

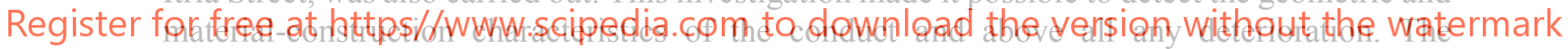

rectangular-shaped conduct with a pseudo-rectilinear course, $0.75 \mathrm{~m}$ width and approximately

1 m height, shows a concrete base, walls with ashlars regularly arranged with bedding mortar joints and a roof made of stone slabs placed side by side and regularly arranged.

From the visual inspection inside the conduct, several water infiltrations were noticed, coming from the side of the church, with low, but still continuous influxes at the base of the conduct. The water that flows into the conduct from the mountain side disappears, significantly, to infiltrate below the concrete base without knowing the path that follows in depth, being the concrete slab damaged in several points, with some portions removed by runoff water within the same conduct.

From the overall picture of the results of the preliminary investigations, it was possible to define the main cause of the collapse in a failure of the foundations of the wall near Itria Street, due to the inconsistency of the underlying ground, presumably due to the runoff and slow removal of material, following water infiltrations from the conduct. The narrowing of the section of the collapsed wall and the excess load of the roof built in the 1980s are, at this point, to be considered secondary causes. 


\section{INTERVENTION METHODOLOGY}

The works completed on 13 September 2019 represented the 1st stage of consolidation and restoration works of the church of Itria, aimed at consolidating the ground below the church, reconstructing the collapsed wall, consolidating the walls and highlighting an underground room, identified as the primitive XIVth century church. In the 2nd stage of consolidation, the interventions on horizontal structures, arches and damaged vaults, the plaster, the floors and the waterproofing and water disposal system will take place.

\subsection{Interventions on the ground}

The results of the investigations made it possible to deepen the knowledge of the building with respect to its current state of conservation and formulate a proposal for intervention assessed based on the historical information and the material data collection.

Consequently, the works management suspended the works and drew up a variation report that took into account the results and at the same time agreed with the conduct managers (Municipality of Piazza Armerina and Acquaenna Ltd) the suitable interventions to prevent water dispersion from the conduct to the ground under the church.

The intervention on the conduct was preparatory to the ground consolidation interventions. In particular, a compensation chamber has been created, upstream of the conduct, to avoid excessive flow in the conduct itself. The concrete at the base of the conduct was restored and the walls and the base were covered with three layers with different performances: polyolefins (TPO), non-woyen fabric (TNT) and draining sheet (Enkadrain type) to allow the drainage of dispersed water and presc For the consolidation aggregating the incoherer After a careful marke
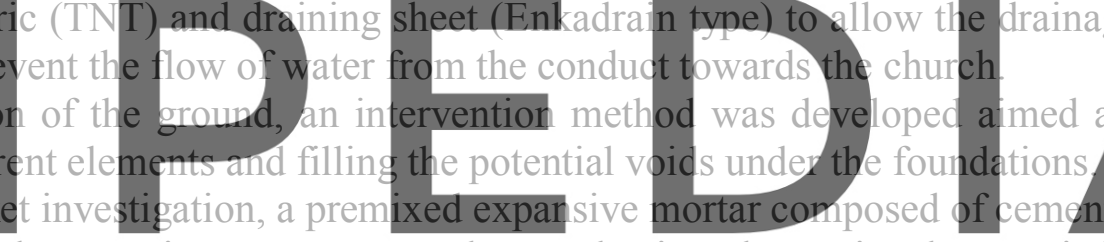

particular additives and expansive agents was chosen, having the main characteristic of


loads in foundations between $1.3 \mathrm{MPa}$ and $11 \mathrm{MPa}$ (Betonfix Espando type by Kimia). It is a material normally used for ground consolidation, filling voids and cavities and tunnel applications for anchoring nails. To ensure its reliability, two tests were carried out on site, one in a $0.30 \times 0.30 \times 0.60 \mathrm{~m}$ metal specimen, with confined expansion, and the other in a $0.50 \times 0.50 \times 0.40 \mathrm{~m}$ excavation inside the Church flooring, with free expansion. Both tests have shown within half an hour an increase in the volume of the mortar cast in situ in the confined case by $100 \%$ and $70 \%$ in the free one (fig. 6).

Once the material was identified, a set of mortar injections was realized through perforations to the external and internal side of the wall on Itria Street and Itria Square, between $0.50 \mathrm{~m}$ and $1 \mathrm{~m}$ distant and between $2 \mathrm{~m}$ and $6 \mathrm{~m}$ depth. The rotation perforations, performed vertically or slightly inclined towards the wall, allowed the insertion of drilled rigid PVC canes with an external diameter of $34 \mathrm{~mm}$ and an internal diameter of $27 \mathrm{~mm}$; the canes equipped with tip caps were equipped with valves not more than $1 \mathrm{~m}$ distant each other.

In order to consolidate even the ground furthest from the holes, it was important to choose the injection pressure. Based on previous experience of the contractor, in similar works, the pressure was chosen varying between $2 \mathrm{~atm}$ and $4 \mathrm{~atm}$, depending on the ground resistance. 

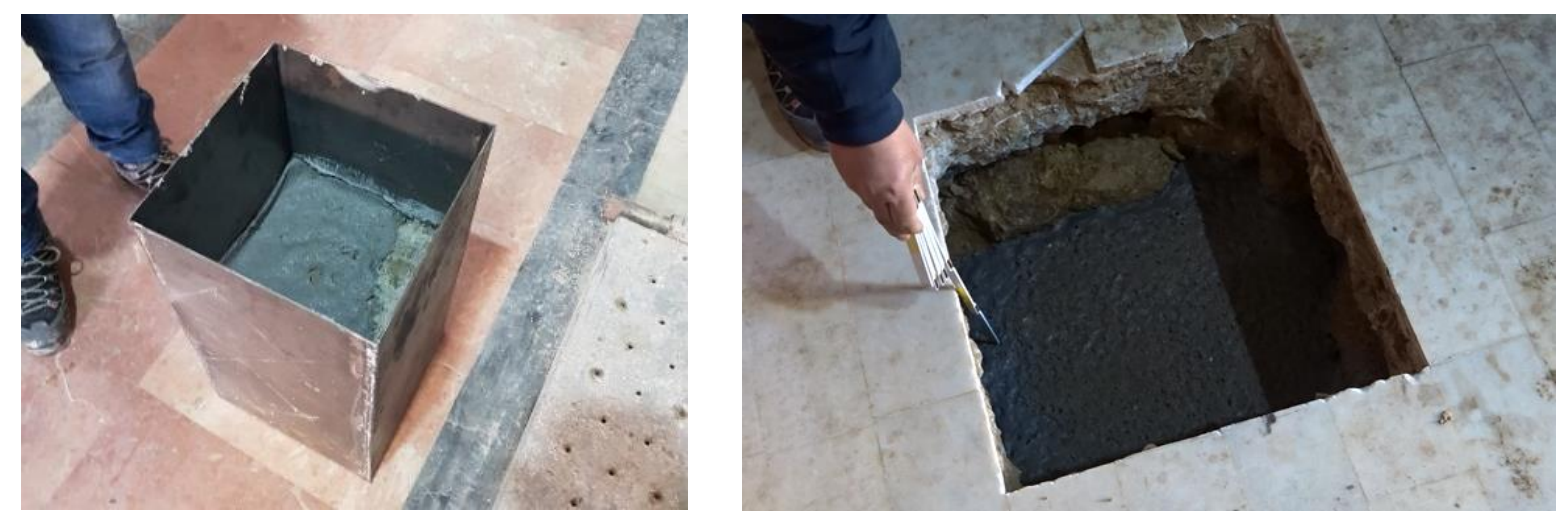

Figure 6: Confined and free expansion test of the expansion mortar

The injections were carried out with staggered perforations and by injecting the material under pressure regulated by a pressure gauge, from the deeper valve, and advancing along the path. Once this stage was completed, the operation was repeated to make the material exit the upper valve, until it was rejected. Once the external injections were completed, the internal injections were placed at higher distance and consuming less mortar, as the ground was already partially consolidated by the material injected through the external perforations (fig. 7).
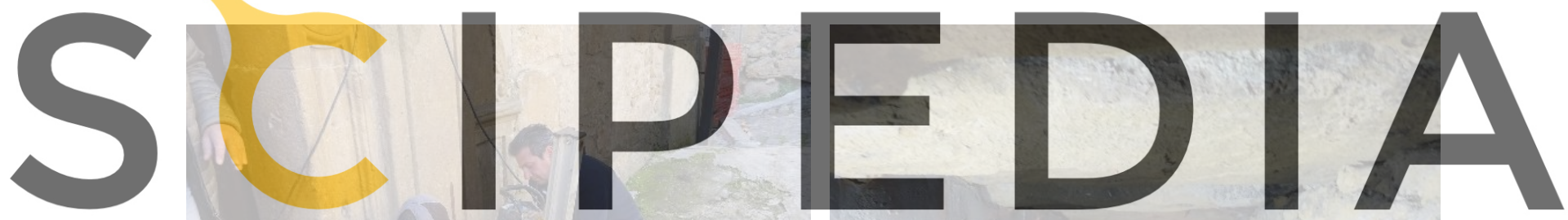

Register for free at https//www.scipedia.com to

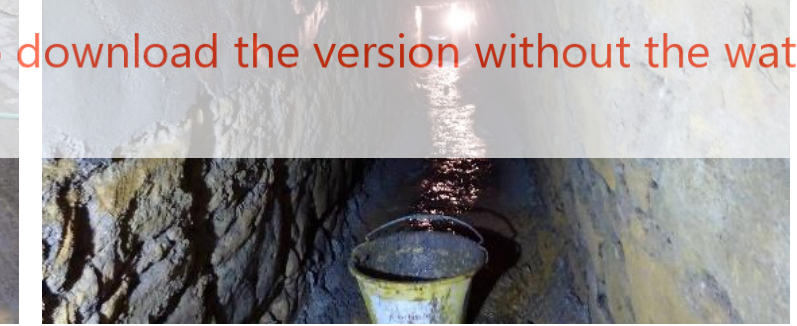

Figure 7: Perforation in the ground and interior view of the conduct

\subsection{Interventions on the building}

Once the foundation ground was consolidated, the enlargement of the wall was dismantled, which over the years had been built to reinforce the base of the wall downstream of Itria Street and which concealed the entrance to the underground compartment discovered by the excavations carried out during the works.

This was part of the primitive XIVth century church with access to the lower part of the current Itria Street and which justifies the characteristic shape of the current church built in the XVIIth century over this first settlement.

From direct observation of the structure, it was found that the failure had not yet stabilized. 
To avoid immediate risks, it was however necessary to take urgent ground consolidation measures below the pillar adjacent to the apse.

Once the rotation of the remaining wall below the collapsed one was verified and the relative deformation, the demolition and the reconstruction of this wall was carried out, by means of stone ashlars of the quarries of Aidone, for almost the entire thickness, and with fair-faced external layer, using the ashlars recovered after the collapse and kept in the Curia spaces. The new wall has a variable thickness, in correspondence with the existing niche, which was no longer built, reaches $2 \mathrm{~m}$.

The works also involved the consolidation of the existing walls of the church and the underground room with injections of fluid cement mortar (BETONFIX 200) and the anchoring of the pillar near the apse to the wall rebuilt with carbon bars and special mortar.

The rebuilt wall was also connected with the opposite wall through new chains in order to improve the box-like behaviour of the entire load-bearing wall structure. In particular, a series of perforations reinforced with carbon rods were made and 3 chains at 3 heights were placed to create the interlocking at the corner of the new wall with the existing orthogonal one: at the foot level of the church, at the roof level and at the intermediate level (fig. 8, 9). Two other chains were built on the sides of the closing arch of the apse.

During the whole-time span of the works, a monitoring system was developed in order to measure any in-progress phenomena or to ascertain the results obtained with the injections of expansive mortar. In particular, crack-gauges and pendulums were applied and left at the end of the works, at the most critical points (e.g. in the cracks of the arches converging in the pillar adjacent to the apse) to measure any structural movements during the suspension of the works.
Considering the importance of ground consolidation for the intervention carried out on the
church, a new electric tomography camprign has been planned for the resumption of the works
of the 2 nd lot in order to verify the filling of the voids and proceed with any additions.

Register for free at https//www.scipedia.com to download the version without the watermark

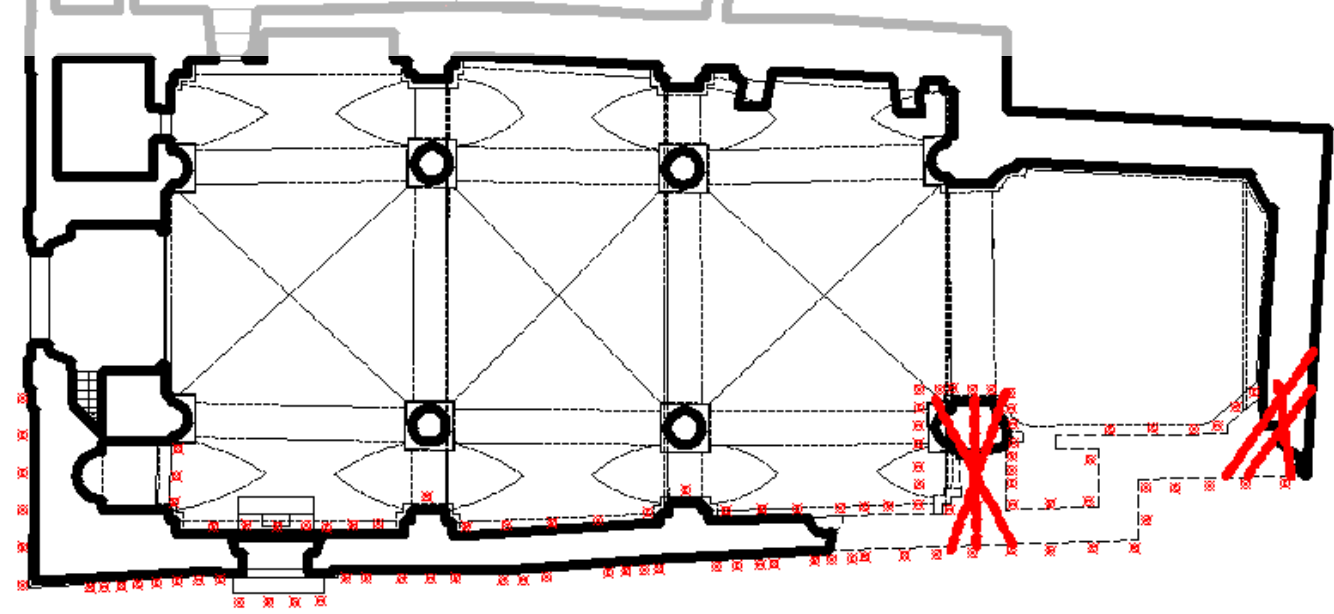

Figure 8: Plan of the church with points of perforation in the ground and with the perforations reinforced with carbon rods placed to create interlocking at the corner of the new wall with the existing one 

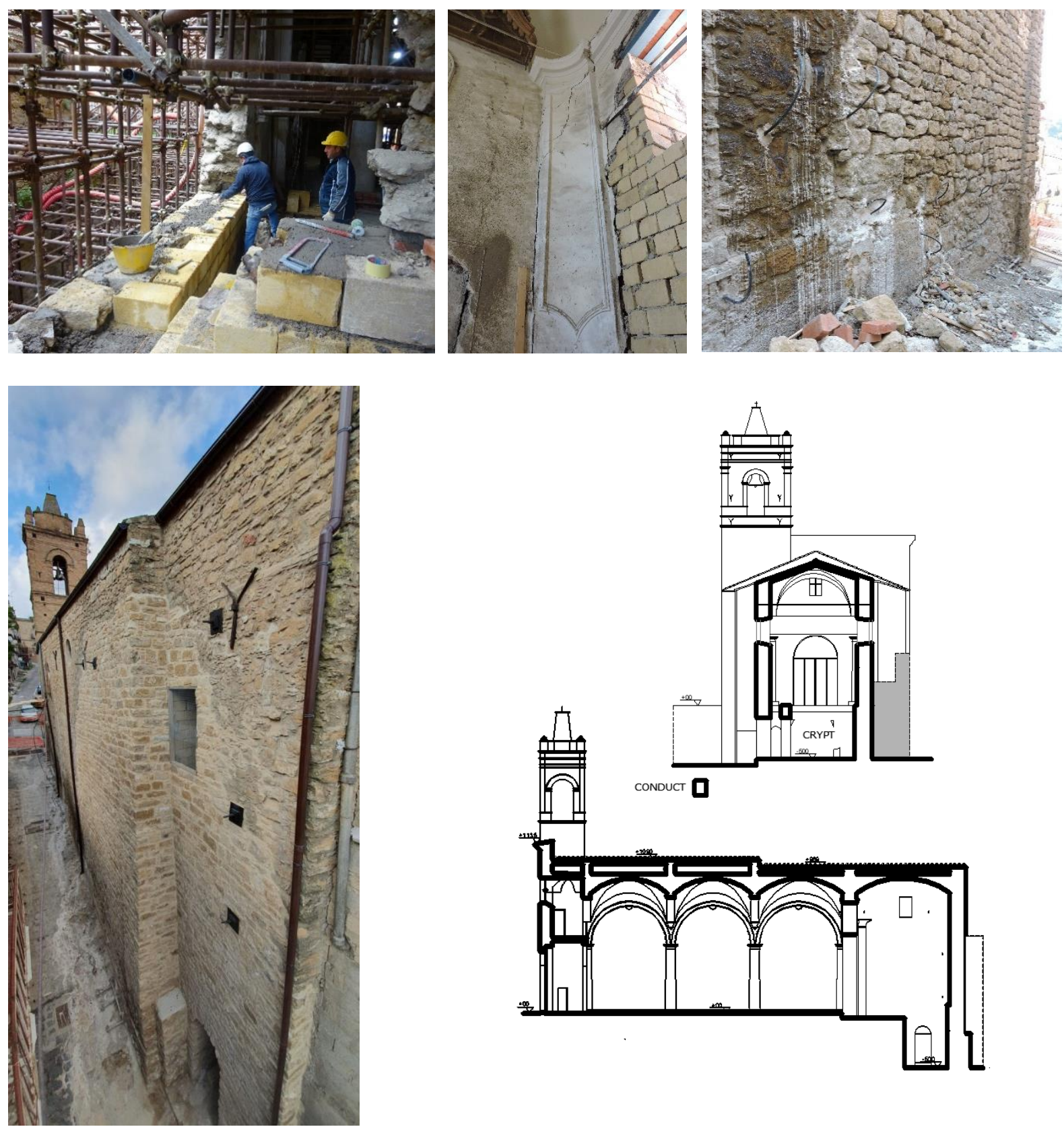

Figure 9: Photographs of the reconstructed wall and drawings of the church with the found underground room

\section{CONCLUSIONS}

The geometric irregularities of the church, due to original imperfections and the joints made during the construction phase of the church at the end of the XVIIth century above the preexisting XIVth century church, as well as the subsequent modifications, have generated a very complex framework that led to errors in the design phase.

In addition, the urban evolution surrounding the church have created a complex situation. With the passage of time, the sacristy and other buildings were joined to the side facade of the church, not in all its length, and on the southern head. But above all, the location of the conduct 
adjacent to the church have led to a disastrous situation.

It is important to highlight how in the case study, as in many restoration projects [8], the complexity of the monument negatively influenced the choice of preliminary investigations and how this negative influence was accentuated by an originally project lacking, by the use of unsuitable materials and subsequent inadequate interventions.

The experience of this case study demonstrates the importance in choosing the types of preliminary investigations and how these can positively or negatively influence the identification of the causes of failure.

In conclusion, it is possible to affirm that with the appropriate preliminary investigations of the ground, it would have been possible to intervene immediately in the conduct and prevent the phenomenon from continuing in the 12 years between the collapse and the start of the works, causing further damage, such as the lowering of the pillar in proximity of the apse and consequently greater interventions and expenses.

Acknowledgements. The restoration works were realized thanks to the C.E.I. (Conferenza Episcopale Italiana) cofounding, together with the Diocese of Piazza Armerina, the 70\% amount of the works. Many thanks to Don Giuseppe Paci, director of the Sacred Art and Cultural Heritage Office of the Diocese of Piazza Armerina and his assistant dott. arch. Tiziana Crocco, surveyor Giovanni Di Manno, technical director of ESSE I Ltd, Regalbuto (EN), executor of the works and geologists Ranieri Santarosa and Nunzio Santarosa, owners of Geotecnhibla Ltd of Avola (SR), carrying out geophysical survey.

\section{REFERENCES}

[1] Gil E., Mas A., Lerma C., Torner M.E., Vercher J., Non-destructive Techniques Methodologies for the Detection of Ancient Structures under Heritage Buildings. International Journal of Architectural Heritage (Published online: 17 Dec 2019).

[2] Basiricò T., Campione S., Cottone A., The collapse and restoration of the Church of Saint Mary of Itria in Piazza Armerina (Sicily, Italy). In: R. Aguilar et al. (Eds.): Structural Analysis of Historical Constructions, RILEM Bookseries 18 (2019), pp. 2016-2024.

[3] Villari L., Storia ecclesiastica della città di Piazza Armerina, Società messinese di Storia Patria, Messina (1988).

[4] Trogu A., Ranieri G., Fischanger F., 3D Electrical Resistivity Tomography to Improve the Knowledge of the Subsoil below Existing Buildings. Environmental Semeiotics (2011) 4 (4):63-70.

[5] Torner M. E., Mas A., Lerma C., Herráez J., Analysis Method for Studying Groundwater under a Church. Applied Mechanics and Materials (2016) 861:263-270.

[6] Comina C., Giordano N., Ghidone G., Fischanger, Time-Lapse 3D Electric Tomography for Short-time Monitoring of an Experimental Heat Storage System, Geosciences (2019) $9(4): 167$.

[7] Cardarelli E., Fischanger F., 2D data modelling by electrical resistivity tomography for complex subsurface geology. Geophysical Prospecting (2006) 54 (2):121-133.

[8] Torner M. E., Mas A., Lerma C., Gil E., Vercher J., Embedding of the Church of the Asunción of Llíria (Spain). Origin and Consequences. Estoa (2019) 16 (8):111-119. 